\title{
In Vitro Propagation of Camellia oleifera Abel. Using Hypocotyl, Cotyledonary Node, and Radicle Explants
}

\author{
Ze Li and Xiaofeng Tan ${ }^{1}$
}

Key Laboratory of Cultivation and Protection for Non-Wood Forest Trees, Ministry of Education, Central South University of Forestry and Technology, Changsha 410004, China; Cooperative Innovation Center of Cultivation and Utilization for Non-Wood Forest Trees of Hunan Province, Central South University of Forestry and Technology, Changsha 410004, China; and Key Lab of Non-wood Forest Products of State Forestry Administration, Central South University of Forestry and Technology, Changsha, Hunan, 410004, China

\section{Zhiming Liu ${ }^{1}$}

Key Laboratory of Cultivation and Protection for Non-Wood Forest Trees, Ministry of Education, Central South University of Forestry and Technology, Changsha 410004, China; Cooperative Innovation Center of Cultivation and Utilization for Non-Wood Forest Trees of Hunan Province, Central South University of Forestry and Technology, Changsha 410004, China; Key Lab of Non-wood Forest Products of State Forestry Administration, Central South University of Forestry and Technology, Changsha, Hunan, 410004, China; and Department of Biology, Eastern New Mexico University, Portales, NM 88130

Qing Lin, Lin Zhang, Jun Yuan, Yanling Zeng, and Lingli Wu

Key Laboratory of Cultivation and Protection for Non-Wood Forest Trees, Ministry of Education, Central South University of Forestry and Technology, Changsha 410004, China; Cooperative Innovation Center of Cultivation and Utilization for Non-Wood Forest Trees of Hunan Province, Central South University of Forestry and Technology, Changsha 410004, China; and Key Lab of Non-wood Forest Products of State Forestry Administration, Central South University of Forestry and Technology, Changsha, Hunan, 410004, China

Additional index words. Camellia oleifera, tissue culture, adventitious shoot, perlite, rooting

Abstract. Camellia oleifera Abel. is one of four major woody oil plants in the world. The objective of the current study was to evaluate the effect of different plant growth regulators (PGRs) and concentrations on direct organogenesis using cotyledonary nodes, hypocotyls, and radicle explants. High induction frequency of adventitious shoots were obtained from cotyledonary nodes, hypocotyls, and radicle explants $(85.2 \%, 73.6 \%$, and 41.0\%, respectively) when cultured on half-strength Murashige and Skoog (1/2 MS) medium containing $2.0 \mathrm{mg} \cdot \mathrm{L}^{-1}$ 6-benzylaminopurine (BA) and $0.1 \mathrm{mg} \cdot \mathrm{L}^{-1}$ indole-3acetic acid (IAA). Microshoots from cotyledonary nodes, hypocotyls, and radicle explants were then transferred to $1 / 2 \mathrm{MS}$ medium containing $2.0 \mathrm{mg} \cdot \mathrm{L}^{-1} \mathrm{BA}$ and $0.05 \mathrm{mg} \cdot \mathrm{L}^{-1}$ indole-3-butyric acid (IBA) for shoot multiplication, resulting in 6.9 shoots per explant. The shoots were transferred to Woody Plant Medium (WPM) supplemented with various $\alpha$-naphthalene acetic acid (NAA) and gibberellic acid $\left(\mathrm{GA}_{3}\right)$ for shoot elongation. The mean length of shoots and the number of leaves per shoot were 3.7 and $6.6 \mathrm{~cm}$, respectively, in WPM supplemented with $0.5 \mathrm{mg} \cdot \mathrm{L}^{-1} \mathrm{NAA}$ and $3.0 \mathrm{mg} \cdot \mathrm{L}^{-1} \mathrm{GA}_{3}$. The highest rooting of shoots $(90.2 \%)$ or the number of roots per shoot (7.2) was obtained when elongated microshoots were transferred to 1/2 MS medium supplemented with $3.5 \%$ perlite, $1.0 \mathrm{mg} \cdot \mathrm{L}^{-1}$ IBA and $2.0 \mathrm{mg} \cdot \mathrm{L}^{-1} \mathrm{NAA}$. The rooted plantlets were successfully acclimatized in the greenhouse with a survival rate of $90.0 \%$. The in vitro plant regeneration procedure described in this study is beneficial for mass propagation and improvement of $C$. oleifera through genetic engineering.

The C. oleifera Abel. (Theaceae) is an important oil producing species native to China. Together with olive (Olea europaea), oil palm
(Elaeis guineensis Jacq.) and coconut (Cocos nucifera $\mathrm{L}$.), they are the four major woody oil trees in the world. C. oleifera seeds are used for in the manufacturing process of tea oil, a high quality cooking oil. C. oleifera is composed of more than $80 \%$ unsaturated fatty acids including oleic, linoleic, and linolenic acid (Liao et al., 2005), which have reported health benefits. For example, tea oil is known to decrease lipid concentrations and prevent hypertension and hardening of arteries (Feas et al., 2013; Zhuang, 2008). A number of bioactive substances have been isolated from tea oil, such as squalene, to create products used to treat aging, tumors, and radiation poisoning (Long and Wang, 2008). To meet demand for tea oil, grain, and oil producing companies have developed technologies for large scale propagation of C. oleifera trees in the south of China (Mo et al., 2010).

Previous studies have regenerated $C$. oleifera using cotyledons of $C$. oleifera clones (Fan et al., 2011; Zhang et al., 2005), buds (Li et al., 2014; Yuan et al., 2013), and somatic embryogenesis ( $\mathrm{Hu}$ et al., 2014). Most of these studies for $C$. oleifera regeneration were based on shoot development from meristematic cells, which had low multiplication rates for adventitious buds and took several months to regenerate. In the Theaceae, it is typically difficult for rooting to occur from in vitro woody shoots, as shown by results of previous studies on C. oleifera (Li et al., 2014; Lü et al., 2013; Zhang et al., 2005). Therefore, it is essential to develop an efficient protocol for $C$. oleifera that decreases the regeneration period. Adventitious shoot organogenesis is an easy and fast plant regeneration method that can be induced via direct or indirect pathways. Hypocotyl explants have been used to achieve regenerated plants in many species including Fraxinus pennsylvanica (Du and Pijut, 2008), pumpkin ash (Fraxinus profunda) (Stevens and Pijut, 2012), carrot (Daucus carota) (Grzebelus et al., 2012), gherkin (Cucumis anguria L.) (Ju et al., 2014), Tamarillo (Cyphomandra betacea) (Kahia et al., 2015) and tung tree (Vernicia fordii) (Lin et al., 2016). However, little research has been conducted using radicles as explants for plant regeneration in $C$. oleifera. Cerezo et al. (2011) established an efficient regeneration system via somatic embryogenesis from radicles of olives. Successful plant regeneration was demonstrated using roots as explants in Brassicas (Sharma and Thorpe, 1989; Wong and Loh, 1988). Cotyledonary node explants were used to regenerate shoots, mainly in species of legume plants including dry bean (Phaseolus vulgaris L.) (McClean and Grafton, 1989), lentil (Lens culinaris) (Bermejo et al., 2012; Chhabra et al., 2008; Warkentin and McHughen, 1993), mung bean (Vigna raditat L. Wilczek) (Gulati and Jaiwal, 1994), and common bean (P. vulgaris) (Arellano et al., 2009; Collado et al., 2013). However, no study to date has reported successful and efficient in vitro propagation and plant regeneration from hypocotyls, cotyledonary nodes, and radicles of C. oleifera. The current study thus evaluates the effect of growth regulators on direct 
organogenesis from hypocotyls, cotyledonary nodes, and radicle explants of $C$. oleifera. The objective of this work is to optimize the explants sources, growth regulators, carbon sources, and perlite for the induction, multiplication, elongation, and rooting of adventitious shoot via direct organogenesis.

\section{Materials and Methods}

Plant materials. Open-pollinated mature C. oleifera seeds were collected at Central South University of Forestry and Technology Germplasm Repository in Dongcheng City, Wangcheng County, Hunan Province, China $\left(113^{\circ} 21^{\prime} \mathrm{E}, 28^{\circ} 05^{\prime} \mathrm{N}\right)$. Samples were collected at an altitude between 60 and $150 \mathrm{~m}$ in a region with an annual average temperature of $19.3{ }^{\circ} \mathrm{C}$, annual mean frost-free duration of 276 to $291 \mathrm{~d}$, and annual mean sunshine duration of $1762 \mathrm{HR}$. The seeds were air-dried with seedcoats removed. Kernels were surface sterilized, first with $75 \%(\mathrm{v} / \mathrm{v})$ ethanol for $30 \mathrm{~s}$, then rinsed 4-5 times with sterile distilled water. Next, the seeds were treated with $0.1 \%(\mathrm{w} / \mathrm{v})$ mercuric chloride $\left(\mathrm{HgCl}_{2}\right)$ solution for $5 \mathrm{~min}$ and rinsed with sterile water 4-5 times to remove excess $\mathrm{HgCl}_{2}$. Seed embryos were then excised and placed aseptically on half-strength MS (Murashige and Skoog, 1962) medium containing 3\% sucrose and $0.65 \%$ agar in glass vials for germination in the dark for $72 \mathrm{~h}$. The seedlings were then grown under white fluorescent lighting $\left(50 \mu \mathrm{mol} \cdot \mathrm{m}^{-2} \cdot \mathrm{s}^{-1}\right)$ for a photoperiod of $14 / 10 \mathrm{~h}$ of light/darkness at a temperature of $26 \pm 2{ }^{\circ} \mathrm{C}$. The hypocotyls $(1.0 \mathrm{~cm}$ long), cotyledonary nodes $(0.8 \mathrm{~cm}$ long), and radicles ( $1.5 \mathrm{~cm}$ long) were used as explants from 21-day-old in vitro seedlings.

Adventitious shoot induction. The cotyledonary nodes, hypocotyls, and radicle explants were excised from 21-day-old in vitro seedlings and transferred to $1 / 2 \mathrm{MS}$ medium containing $3 \%$ sucrose and $0.65 \%$ agar supplemented with BA $(0,1.0,2.0$, and $\left.3.0 \mathrm{mg} \cdot \mathrm{L}^{-1}\right)$ and IAA $\left(0,0.1\right.$, and $\left.0.5 \mathrm{mg} \cdot \mathrm{L}^{-1}\right)$ for direct adventitious shoot induction (Table 1). Explants were maintained for $2 \mathrm{~d}$ at 26 $\pm 2{ }^{\circ} \mathrm{C}$ in the dark and then exposed to 50 $\mu \mathrm{mol} \cdot \mathrm{m}^{-2} \cdot \mathrm{s}^{-1}$ of lighting with a light/dark cycle of $14 / 10 \mathrm{~h}$. A total of 180 explants (60 explants per replicate) were cultured in 30 flasks for each combination with three replicates. After $45 \mathrm{~d}$, the differentiation rate of adventitious shoots was counted.

Multiple shoots formation. Adventitious shoots from cotyledonary nodes, hypocotyls, and radicles were excised after $45 \mathrm{~d}$ in culture and transferred to $1 / 2 \mathrm{MS}$ medium containing $3 \%$ sucrose and $0.65 \%$ agar supplemented with BA $\left(0,1.0,2.0,3.0\right.$, and $\left.5.0 \mathrm{mg} \cdot \mathrm{L}^{-1}\right)$ and

\footnotetext{
Received for publication 16 Nov. 2015. Accepted for publication $20 \mathrm{Jan} .2016$.

This study was supported by the major projects of science and technology project of Hunan province (2013FJ1006-3)

${ }^{1}$ Corresponding author. E-mail: tanxiaofengen@ 126.com; zhiming.liu@enmu.edu.
}

IBA $\left(0,0.05\right.$, and $\left.0.1 \mathrm{mg} \cdot \mathrm{L}^{-1}\right)$ (Table 2$)$ under $50 \mu \mathrm{mol} \cdot \mathrm{m}^{-2} \cdot \mathrm{s}^{-1}$ of light for multiple shoot formation. After $30 \mathrm{~d}$, the first proliferation coefficient of multiple shoots was calculated as the number of adventitious shoots after inoculation divided by the number of adventitious shoots before inoculation. The media were then replaced by transferring explants to identical fresh media for the second proliferation. After $30 \mathrm{~d}$, the second proliferation coefficient of adventitious shoots was calculated using the aforementioned formula.

Shoot elongation. The adventitious shoots were cut apart and transferred to flasks containing WPM (Lloyd and McCown, $1981)$ supplemented with NAA $(0,0.5,1.0$, and $\left.2.0 \mathrm{mg} \cdot \mathrm{L}^{-1}\right)$, and $\mathrm{GA}_{3}(0,2.0,3.0$, and 5.0 $\left.\mathrm{mg} \cdot \mathrm{L}^{-1}\right)$ and incubated under $50 \mu \mathrm{mol} \cdot \mathrm{m}^{-2} \cdot \mathrm{s}^{-1}$ of light for shoot elongation culture (Table 3 ). A total of 60 shoots per combination were cultured in 30 flasks, and the experiment was repeated three times. After $30 \mathrm{~d}$, the length of the shoots and number of leaves were recorded.

Rooting and acclimatization. When elongated, adventitious shoots reached $3-4 \mathrm{~cm}$ in length; they were cut off at the base and transferred to a half-strength MS medium containing $2 \%$ sucrose and $0.25 \%$ phytagel (Sigma) supplemented with $35 \mathrm{~g} \cdot \mathrm{L}^{-1}$ perlite and several concentrations combination of $\operatorname{IBA}\left(0,0.5,1.0\right.$, and $\left.2.0 \mathrm{mg} \cdot \mathrm{L}^{-1}\right)$ and NAA $(0$, $1.0,2.0$, and $3.0 \mathrm{mg} \cdot \mathrm{L}^{-1}$ ) (Table 4) to induce roots. Explants were maintained for $3 \mathrm{~d}$ at $26 \pm 2{ }^{\circ} \mathrm{C}$ in the dark and then exposed to $50 \mu \mathrm{mol} \cdot \mathrm{m}^{-2} \cdot \mathrm{s}^{-1}$ of light with a light/dark cycle of $14 / 10$ h. After 6 weeks of culturing, the rooting frequency, number, length, and number of lateral roots per shoot were recorded. A total of 60 explants were cultured and one shoot was cultured per flask for each combination, and each experiment was repeated three times.

The rooted plantlets, which had 5-6 leaves at $6-7 \mathrm{~cm}$ in length, were removed from the flasks, and the agar was washed in running tap water. Sixty plantlets were transferred to plastic pots $(15 \mathrm{~cm}$ in diameter $\times 12 \mathrm{~cm}$ high $)$ containing a mixture of peatmoss, perlite, and loess $(1: 1: 1, \mathrm{v} / \mathrm{v} / \mathrm{v})$, and the pots were covered with plastic bags. The pots were then placed in a greenhouse with $80 \%$ relative humidity for a $12 \mathrm{~h}$ photoperiod $\left(60 \mu \mathrm{mol} \cdot \mathrm{m}^{-2} \cdot \mathrm{s}^{-1}\right)$. The plastic bags were gradually removed over a period of 1-2 weeks in the greenhouse to acclimatize the ambient conditions. Plants were watered every $2-3 \mathrm{~d}$ until the bags were fully opened and then watered as needed. After a month, the plants were transferred to the field and watered moderately. Plant survival rate was calculated after $45 \mathrm{~d}$.

Statistical analysis. All the experiments were laid out in a completely randomized design with three replicates and each treatment contained 60 explants except for acclimatization. The data were expressed as mean \pm SE. The mean values and standard errors were calculated using Excel 2007. Statistical analysis included one-way analysis of variance followed by Duncan's multiple range test at $P<0.05$; analysis was performed using SPSS17.0.

\section{Results and Discussion}

The microshoots regeneration occurred via direct organogenesis from cotyledonary nodes (Fig. 1A), hypocotyls (Fig. 1C), and radicle explants (Fig. 1E) of C. oleifera. For adventitious shoot induction, the best percent shoot regeneration for cotyledonary nodes $(85.2 \%)$, hypocotyls $(73.6 \%)$, and radicle $(41.0 \%)$ explants produced adventitious shoots without an intervening callus when cultured on optimum regeneration 1/2 MS medium supplemented with $2.0 \mathrm{mg} \cdot \mathrm{L}^{-1} 6$-BA with $0.1 \mathrm{mg} \cdot \mathrm{L}^{-1}$ IAA (Table 1 ). Major differences between the three organs were found, with the most efficient $C$. oleifera organ being the cotyledonary nodes, followed by the hypocotyls (Table 1). Moreover, radicle tissue showed poor regeneration and the lowest number of shoots per explant among the three organs, which was consistent with previous studies in Brassica napus (Kamal et al., 2007). Hypocotyl explants proved to be more suitable than cotyledonary nodes and radicle but overall less productive than cotyledonary nodes in $C$. oleifera shoot direct organogenesis, contrasting previous studies that hypocotyls were the most suitable explants for plant regeneration and transformation (Cardoza and Stewart, 2004). When used as an explant to induce adventitious shoots, cotyledonary nodes showed higher regeneration efficiency. A successful early cotyledonary nodes adventitious organogenesis had also been reported in lentil (Bermejo et al., 2012). In addition, several studies demonstrated that the emergence of adventitious shoots from the cotyledonary petioles was simple (Huang et al., 2014; Song et al., 2011; Sujatha et al., 2012). Such adventitious shoots were restored from epidermal cells with high mitotic activity possibly because epidermal cells of cotyledonary petiole may retain the characteristics of parenchyma cells. Shoots regenerated from cotyledonary nodes were viable and more vigorous than those regenerated from hypocotyls and radicle explants. However, the number of regenerated shoots in hypocotyl explants was higher than cotyledonary nodes (Table 1). These results were similar to those of previous studies on Campanula punctata (Sivanesan et al., 2011) and yam (Dioscorea sp.) (Anike et al., 2012), in which the petioles of the cotyledons retained sufficient cellular plasticity to achieve plantlet regeneration or direct organogenesis.

In our study, the occurrence of organogenesis on cotyledonary nodes, hypocotyls, and radicle explants significantly depended on PGR supplemented in culture media (Table 1). There were no adventitious shoots produced from cotyledonary nodes, hypocotyls, and radicles on PGR-free medium. Adventitious shoot formation was observed on all BA and IAA concentrations tested and a positive correlation was noted between the BA concentration and shoot formation rate of three explants (Table 1). Cytokinin at appropriate concentrations was the prerequisite for induction of adventitious shoot. BA has been 
Table 1. Effects of different hormonal combinations on adventitious shoot induction from freshly isolated cotyledonary nodes, hypocotyls, and radicles of Camellia oleifera.

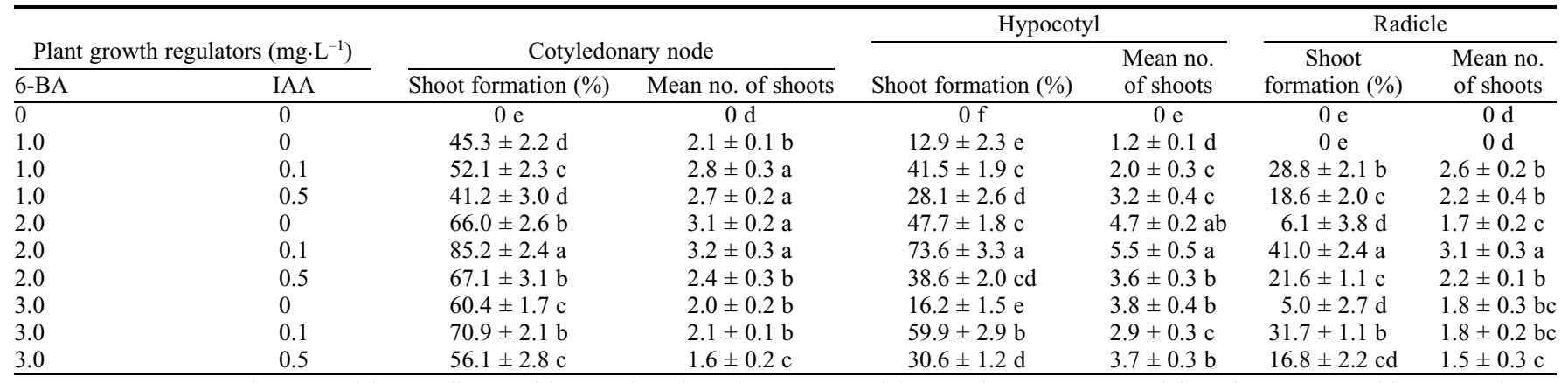

Data represents mean values \pm SE of three replicates with 20 explants in each treatment and the experiment was repeated three times. Means with common letters are not significantly different at $P \leq 0.05$ according to Duncan's multiple range test.

6-BA = 6-benzylaminopurine; IAA = indole-3-acetic acid.

Table 2. The effect of the combination of 6-BA and IBA in 1/2 MS medium on adventitious shoot proliferation coefficient of Camellia oleifera.

\begin{tabular}{llcc}
\hline \multicolumn{2}{c}{ Plant growth regulators $\left(\mathrm{mg} \cdot \mathrm{L}^{-1}\right)$} & & \\
\cline { 1 - 1 } 6-BA & IBA & First proliferation coefficient & Second proliferation coefficient \\
\hline 0 & 0 & $1.0 \pm 0 \mathrm{c}$ & $1.0 \pm 0 \mathrm{~d}$ \\
1.0 & 0.05 & $1.6 \pm 0.1 \mathrm{bc}$ & $3.8 \pm 0.3 \mathrm{~cd}$ \\
2.0 & 0 & $1.7 \pm 0.1 \mathrm{~b}$ & $4.2 \pm 0.4 \mathrm{c}$ \\
2.0 & 0.05 & $2.8 \pm 0.3 \mathrm{a}$ & $6.9 \pm 0.5 \mathrm{a}$ \\
2.0 & 0.1 & $2.2 \pm 0.2 \mathrm{~b}$ & $5.5 \pm 0.4 \mathrm{~b}$ \\
3.0 & 0.05 & $2.4 \pm 0.1 \mathrm{ab}$ & $5.7 \pm 0.4 \mathrm{~b}$ \\
3.0 & 0.1 & $1.9 \pm 0.2 \mathrm{~b}$ & $4.6 \pm 0.3 \mathrm{c}$ \\
5.0 & 0.05 & $1.8 \pm 0.3 \mathrm{~b}$ & $3.9 \pm 0.3 \mathrm{~cd}$ \\
\hline
\end{tabular}

Data represents mean values \pm SE of three replicates with 20 explants in each treatment and the experiment was repeated three times. Means with common letters are not significantly different at $P \leq 0.05$ according to Duncan's multiple range test.

6-BA = 6-benzylaminopurine; IBA = indole-3-butyric acid; MS = Murashige and Skoog.

Table 3. Effects of different hormonal combinations on Camellia oleifera shoot elongation and strengthening in WPM.

\begin{tabular}{|c|c|c|c|}
\hline \multicolumn{2}{|c|}{ Plant growth regulators $\left(\mathrm{mg} \cdot \mathrm{L}^{-1}\right)$} & \multirow[b]{2}{*}{ Length of shoots $(\mathrm{cm})$} & \multirow[b]{2}{*}{ No. of leaves } \\
\hline$\overline{\mathrm{NAA}}$ & $\mathrm{GA}_{3}$ & & \\
\hline$\overline{0}$ & 0 & $1.3 \pm 0.1 \mathrm{~d}$ & $2.2 \pm 0.2 \mathrm{~d}$ \\
\hline 0.5 & 2.0 & $3.2 \pm 0.4 \mathrm{ab}$ & $4.8 \pm 0.4 \mathrm{c}$ \\
\hline 0.5 & 3.0 & $3.7 \pm 0.5 \mathrm{a}$ & $6.6 \pm 0.3 \mathrm{a}$ \\
\hline 0.5 & 5.0 & $3.5 \pm 0.3 \mathrm{a}$ & $5.8 \pm 0.4 \mathrm{ab}$ \\
\hline 1.0 & 3.0 & $3.2 \pm 0.4 \mathrm{ab}$ & $4.3 \pm 0.3 \mathrm{c}$ \\
\hline 2.0 & 3.0 & $2.8 \pm 0.2 \mathrm{c}$ & $3.9 \pm 0.2 \mathrm{~cd}$ \\
\hline
\end{tabular}

Data represents mean values $\pm \mathrm{SE}$ of three replicates with 20 explants in each treatment and the experiment was repeated three times. Means with common letters are not significantly different at $P \leq 0.05$ according to Duncan's multiple range test.

$\mathrm{NAA}=\alpha$-naphthalene acetic acid; $\mathrm{GA}_{3}=$ gibberellic acid; $\mathrm{WPM}=$ Woody Plant Medium

well documented as a powerful inducer of shoot direct regeneration and multiplication (Al Malki and Elmeer, 2010; Bermejo et al., 2012; Joshi and Kothari, 2007; Lü et al., 2013; Sanatombi and Sharma, 2008). However, we found that BA concentrations higher than $2.0 \mathrm{mg} \cdot \mathrm{L}^{-1}$ in combination with IAA had a negative effect on $C$. oleifera direct adventitious shoot formation (Table 1). This result was similar to those of previous studies on pumpkin ash (Huang et al., 2014; Stevens and Pijut, 2012). Therefore, the concentration of appropriate PGR was important for early establishment of shoot regeneration.

In hormone-free medium, the multiplication index was still one (Table 2). 1/2 MS medium supplemented with only BA could produce multiple shoots and the second multiplication index could reach 4.2, however, the multiple shoots were not strong enough. Moreover, the greatest proliferation occurred in $1 / 2$ MS medium containing $2.0 \mathrm{mg} \cdot \mathrm{L}^{-1} \mathrm{BA}$ and $0.05 \mathrm{mg} \cdot \mathrm{L}^{-1} \mathrm{IBA}$, and the first proliferation coefficient and second proliferation coefficient were 2.8 (Fig. 1F) and 6.9 (Fig. 1G), respectively. Interestingly, the number of available shoots per explant decreased when IBA concentrations exceeded $0.05 \mathrm{mg} \cdot \mathrm{L}^{-1}$ (Table 2). It has been reported that appropriate concentrations of $\mathrm{BA}$ is beneficial for shoot proliferation (Dragan, 1989). Our results indicate that the best adventitious shoot proliferation was obtained by a combination of BA and low concentration of IBA. The adventitious shoot not only proliferated quickly, but also grew well and the results were consistent with previous studies (Lü et al., 2013; Mondal et al., 2004). Moreover, Huang et al. (2014) reported that the shoots produced at higher concentrations of 6-BA were distorted and often pale green, with a light, glassy appearance. In the process of subculture multiplication for Camellia tissue culture, MS basal medium was the most commonly used medium during proliferation, whereas $1 / 2 \mathrm{MS}$ medium was seldom used (Lü et al., 2013; Mondal, 2011). In this study, we found that adventitious shoots were not easy to develop into multiple shoots when using MS medium. We also compared MS and 1/2 MS medium on multiple shoot formation from $C$. oleifera adventitious shoots; our results indicated that 1/2 MS medium was significantly better than MS medium (data not shown).

Regeneration of strong and healthy shoots is the key step in plant rooting. After $30 \mathrm{~d}$ in culture, the adventitious shoots were excised and inoculated for elongation. The length of shoots and number of leaves were measured after $30 \mathrm{~d}$ in culture. When NAA concentration was constant, the length of shoots and number of leaves first increased and then decreased as $\mathrm{GA}_{3}$ concentration increased. The length of shoots and number of leaves reached the maximum value at 3.7 and $6.6 \mathrm{~cm}$ (Fig. 1H) in the WPM supplemented with NAA of $0.5 \mathrm{mg} \cdot \mathrm{L}^{-1}$ and $\mathrm{GA}_{3}$ of $3.0 \mathrm{mg} \cdot \mathrm{L}^{-1}$, respectively. Under such culture conditions, the shoots were dark green and showed high growth vigor, which was good for subsequent rooting culture. Increasing $\mathrm{GA}_{3}$ and reducing cytokinins would have been helpful for shoot elongation and growth, which was consistent to those results obtained from Feijoa [Acca sellowiana (Berg) Burret], Campanula punctate Lam. var. rubriflora and pumpkin ash (F. profunda) (Cangahuala-Inocente et al., 2007; Sivanesan et al., 2011; Stevens and Pijut, 2012).

The shoots measuring $3-4 \mathrm{~cm}$ in height were inoculated into rooting medium containing $3.5 \%$ perlite supplemented with different concentrations of IBA and NAA for rooting culture (Table 4). No root was developed on auxin-free medium. The addition of NAA to the culture medium along with IBA improved rooting percentages and there was a significant effect on root length and number of lateral roots. Exogenous auxin IBA also had a significant effect on root induction rates and the number of roots, 
compared with the control treatment (IBAfree medium) (Table 4). The addition of perlite in the rooting medium, supplemented with $1.0 \mathrm{mg} \cdot \mathrm{L}^{-1} \mathrm{IBA}$ and $2.0 \mathrm{mg} \cdot \mathrm{L}^{-1} \mathrm{NAA}$, resulted in more than $90.0 \%$ root induction (Fig. 1I and J). Rooting medium supplemented with NAA alone did not produce roots from the shoots. IBA used alone had a better effect on root formation than NAA, but root length and number of lateral roots were decreased (Fig. 2C), which is consistent with previous studies (Huang et al., 2014; Patil et al., 2011; Stevens and Pijut, 2012). NAA also led to the formation of a callus at the base of shoots with low rooting rate, making it difficult for acclimatization and transplantation (Fig. 2B). It has been reported that $1 / 2$ MS or $1 / 2$ WPM supplemented with the auxin was useful in inducing root formation in common ash (Fraxinus excelsior) and Llex crenata Thunb, and that a low concentration of inorganic salt was good for plant rooting and root growth (Tabrett and Hammatt, 1992; Yang et al., 2015). In our study, 1/2 MS medium was better than MS for the rooting of $C$. oleifera supplemented with auxin and perlite (data not shown).

The rooting was a difficult part in the in vitro culture of $C$. oleifera; only one root was produced and the root system barely grew into the culture medium. Also the cultivate period was too long (Fig. 2A). Various methods have been developed to overcome the difficulties of rooting, such as ex vitro rooting and two-step rooting that transfers explants into a new culture medium (Yuan et al., 2013). In this study, perlite was added to the rooting medium, which induced root formation successfully (Fig. 2D-F). This is the first report of adding perlite to increase the roots and improve the rooting rate of $C$. oleifera. Continued growth and normal development of rooted plantlets were observed in 3 weeks of culture; well-developed plantlets were transferred to plastic pots containing mixed substrates of peatmoss, perlite, and loess $(1: 1: 1, \mathrm{v} / \mathrm{v} / \mathrm{v})($ Fig. $1 \mathrm{~K})$. The plants were successfully acclimatized in the greenhouse and finally transferred to the field with $90.0 \%$ of survival rate (Fig. 1L), which can be used for conservation and plantation purposes.

In conclusion, this study established, for the first time, a simple propagation protocol for plantlet regeneration of $C$. oleifera using cotyledonary nodes, hypocotyls, and radicles as explants. Our study showed that the morphogenetic potential of cotyledonary nodes and hypocotyls renders these organs as highly valuable explant tissue, whereas the radicle exhibits low regenerative potential. From these results, it is highly possible that this protocol can be used in the future for

Table 4. Effect of different concentrations of NAA or IBA on in vitro root formation of Camellia oleifera shoots in $1 / 2$ MS medium.

\begin{tabular}{|c|c|c|c|c|c|c|}
\hline \multicolumn{7}{|c|}{ Plant growth regulators $\left(\mathrm{mg} \cdot \mathrm{L}^{-1}\right)$} \\
\hline$\overline{\mathrm{IBA}}$ & NAA & Perlite $\left(\mathrm{g} \cdot \mathrm{L}^{-1}\right)$ & Rooting (\%) & Mean no. of roots & Mean root length $(\mathrm{cm})$ & Mean no. of lateral roots \\
\hline$\overline{0}$ & 1.0 & 35.0 & $0 \mathrm{f}$ & $0 \mathrm{e}$ & $0 \mathrm{~d}$ & $0 \mathrm{~d}$ \\
\hline 0.5 & 0 & 35.0 & $40.2 \pm 2.2 \mathrm{~d}$ & $4.2 \pm 0.2 \mathrm{bc}$ & $1.2 \pm 0.1 \mathrm{c}$ & $1.5 \pm 0.1 \mathrm{~b}$ \\
\hline 0.5 & 1.0 & 35.0 & $55.2 \pm 3.2 \mathrm{c}$ & $5.1 \pm 0.2 b$ & $3.9 \pm 0.2 \mathrm{a}$ & $7.9 \pm 0.2 \mathrm{a}$ \\
\hline 1.0 & 1.0 & 35.0 & $80.3 \pm 2.3 b$ & $7.0 \pm 0.3 \mathrm{a}$ & $4.0 \pm 0.3 \mathrm{a}$ & $7.5 \pm 0.1 \mathrm{a}$ \\
\hline 1.0 & 2.0 & 35.0 & $90.2 \pm 3.5 \mathrm{a}$ & $7.2 \pm 0.4 \mathrm{a}$ & $4.2 \pm 0.3 \mathrm{a}$ & $8.8 \pm 0.3 \mathrm{a}$ \\
\hline 1.0 & 3.0 & 35.0 & $79.2 \pm 2.1 \mathrm{~b}$ & $6.8 \pm 0.4 \mathrm{a}$ & $4.2 \pm 0.2 \mathrm{a}$ & $7.4 \pm 0.4 \mathrm{a}$ \\
\hline 2.0 & 2.0 & 35.0 & $75.3 \pm 2.9 \mathrm{~b}$ & $5.5 \pm 0.3 b$ & $4.1 \pm 0.3 \mathrm{a}$ & $7.3 \pm 0.3 \mathrm{a}$ \\
\hline 0 & 1.0 & 0 & $0 \mathrm{f}$ & $0 \mathrm{e}$ & $0 \mathrm{~d}$ & $0 \mathrm{~d}$ \\
\hline 0.5 & 1.0 & 0 & $35.2 \pm 2.1 \mathrm{e}$ & $2.2 \pm 0.3 \mathrm{c}$ & $1.2 \pm 0.3 \mathrm{c}$ & $0 \mathrm{~d}$ \\
\hline 1.0 & 1.0 & 0 & $43.0 \pm 2.3 \mathrm{~d}$ & $2.6 \pm 0.2 \mathrm{c}$ & $2.1 \pm 0.2 \mathrm{~b}$ & $0 \mathrm{~d}$ \\
\hline 1.0 & 2.0 & 0 & $52.8 \pm 3.0 \mathrm{c}$ & $2.8 \pm 0.3 \mathrm{c}$ & $2.3 \pm 0.3 b$ & $0.6 \pm 0.3 \mathrm{c}$ \\
\hline 1.0 & 3.0 & 0 & $46.2 \pm 1.7 \mathrm{~cd}$ & $1.8 \pm 0.3 \mathrm{c}$ & $3.3 \pm 0.2 \mathrm{ab}$ & $1.8 \pm 0.3 b$ \\
\hline 2.0 & 2.0 & 0 & $42.54 \pm 2.6 \mathrm{~d}$ & $1.3 \pm 0.2 \mathrm{~d}$ & $2.8 \pm 0.2 \mathrm{~b}$ & $1.5 \pm 0.2 \mathrm{~b}$ \\
\hline
\end{tabular}

The values represent the mean values $\pm \mathrm{SE}$ of three independent experiments. At least 20 explants were used for each experiment. Means with common letters are not significantly different at $P \leq 0.05$ according to Duncan's multiple range test.

$\mathrm{IBA}=$ indole-3-butyric acid; NAA $=\alpha$-naphthalene acetic acid; MS $=$ Murashige and Skoog.
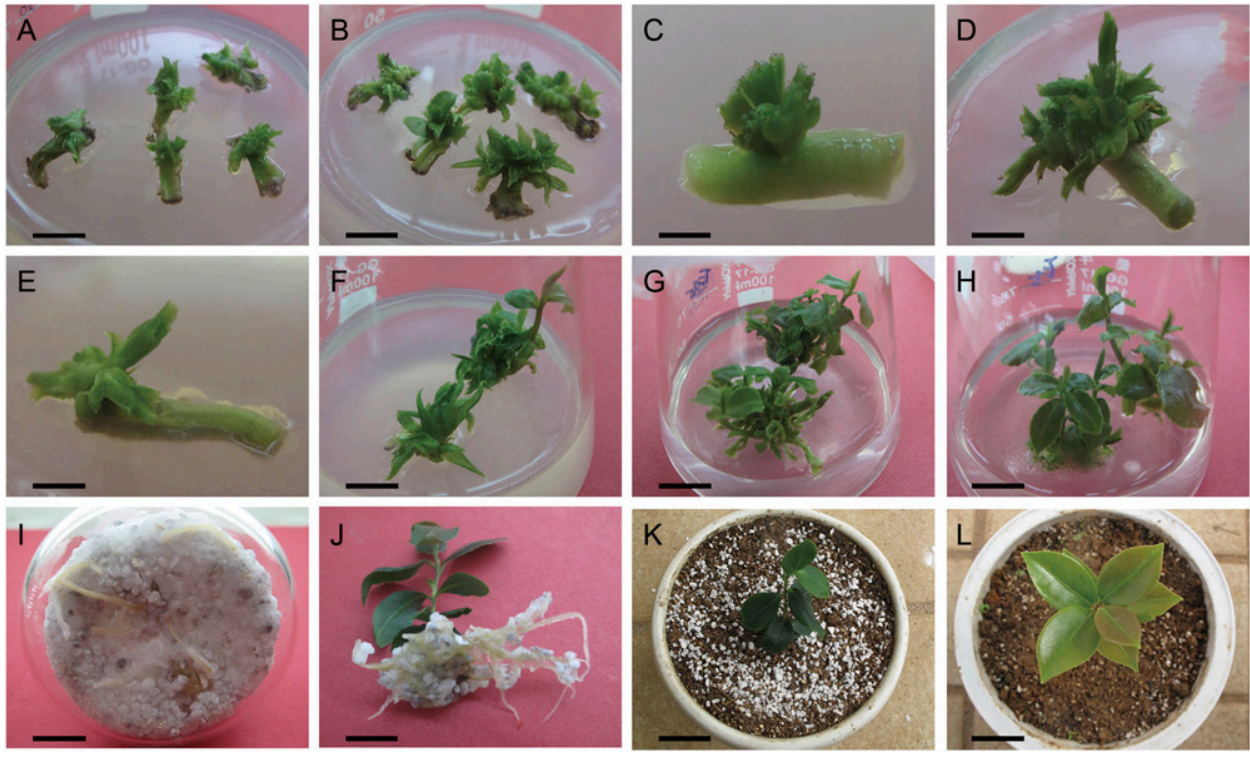

Fig. 1. Plant regeneration from cotyledonary nodes, hypocotyls, and radicle explants of Camellia oleifera. (A, B) Initial stage after 3 and 5 weeks of adventitious shoot induction from cotyledonary nodes explants $(\mathrm{bar}=1 \mathrm{~cm}) .(\mathbf{C}, \mathbf{D})$ Initial stage after 3 and 5 weeks of adventitious shoot induction from hypocotyls explants $(\mathrm{bar}=0.5 \mathrm{~cm})$. (E) Fully formed adventitious shoot from radicle after 5 weeks $(\mathrm{bar}=0.5 \mathrm{~cm}) .(\mathbf{F}, \mathbf{G})$ Microshoot multiplication after 1 and 3 weeks (bar $=1 \mathrm{~cm}$ in F; bar $=1.5 \mathrm{~cm}$ in G). $(\mathbf{H})$ Shoot elongation and strengthening. $(\mathbf{I}, \mathbf{J})$ Successfully rooted plants $($ bar $=1.5 \mathrm{~cm})$. $(\mathbf{K})$ Regenerated plantlets transplant after acclimatization $(\mathrm{bar}=3 \mathrm{~cm})$. (L) Acclimatization of plantlets to the greenhouse after 10 weeks $(\mathrm{bar}=3 \mathrm{~cm})$. 

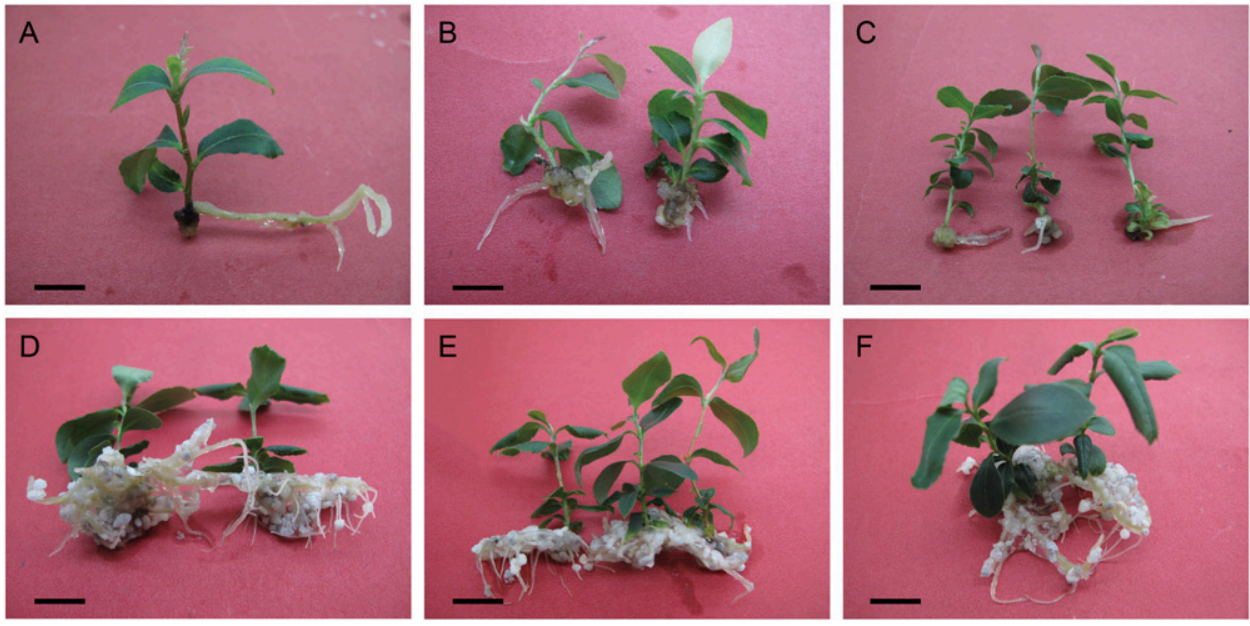

Fig. 2. Effects of perlite and auxin on rooting culture of Camellia oleifera. (A-C) Failing rooted plants on 1/2 Murashige and Skoog (MS) medium containing $1.0 \mathrm{mg} \cdot \mathrm{L}^{-1}$ indole-3-butyric acid (IBA) and $2.0 \mathrm{mg} \cdot \mathrm{L}^{-1} \alpha$-naphthalene acetic acid (NAA) without perlite (bar $\left.=2.0 \mathrm{~cm}\right)$. (D-F) Successfully rooted plants on $1 / 2$ MS medium containing $35 \mathrm{~g} \cdot \mathrm{L}^{-1}$ perlite supplemented with $1.0 \mathrm{mg} \cdot \mathrm{L}^{-1} \mathrm{IBA}$ and $2.0 \mathrm{mg} \cdot \mathrm{L}^{-1} \mathrm{NAA}(\mathrm{bar}=2.0 \mathrm{~cm})$.

rapid mass propagation and germplasm conservation exchange. The protocol might also be useful for agrobacterium-mediated transformation to introduce genes for increasing resistance of this important species.

\section{Literature Cited}

Al Malki, A.A.H.S. and K.M.S. Elmeer. 2010. Influence of auxin and cytokinine on in vitro multiplication of Ficus anastasia. Afr. J. Bio. 9:635-639.

Anike, F.N., K. Konan, K. Olivier, and H. Dodo. 2012. Efficient shoot organogenesis in petioles of yam (Dioscorea spp). Plant Cell Tiss. Org. Cult. 111:303-313.

Arellano, J., S.I. Fuentes, P. Castillo-Espana, and G. Hernández. 2009. Regeneration of different cultivars of common bean (Phaseolus vulgaris L.) via indirect organogenesis. Plant Cell Tiss. Org. Cult. 96:11-18.

Bermejo, C., M.A. Espósito, V. Cravero, F.L. Anido, and E. Cointry. 2012. In vitro plant regeneration from cotyledonary nodes of recombinant inbred lines of lentil. Sci. Hort. 134:13-19.

Cangahuala-Inocente, G.C., L.L.D. Vesco, D. Steinmacher, A.C. Torres, and M.P. Guerra. 2007. Improvements in somatic embryogenesis protocol in Feijoa (Accasellowiana (Berg) Burret): Induction, conversion and synthetic seeds. Sci. Hort. 111:228-234.

Cardoza, V. and C.N. Stewart. 2004. Brassica biotechnology: Progress in cellular and molecular biology. In Vitro Cell. Dev. Biol. Plant 40:542-551.

Cerezo, S., J.A. Mercado, and F. Pliego-Alfaro. 2011. An efficient regeneration system via somatic embryogenesis in olive. Plant Cell Tiss. Org. Cult. 106:337-344.

Chhabra, G., D. Chaudhary, M. Varma, M. Sainger, and P.K. Jaiwal. 2008. TDZ-induced direct shoot organogenesis and somatic embryogenesis on cotyledonary node explants of lentil (Lens culinaris Medik.). Physiol. Mol. Biol. Plants 14:347-353.

Collado, R., N. Veitía, I. Bermúdez-Caraballoso, L.R. García, D. Torres, C. Romero, J.L. Rodríguez Lorenzo, and G. Angenon. 2013. Efficient in vitro plant regeneration via indirect organogenesis for different common bean cultivars. Sci. Hort. 153:109-116.
Dragan, V. 1989. In vitro propagation of greenfoliaged Dracaena fragrans Ker. Plant Cell Tiss. Org. Cult. 17:13-19.

Du, N. and P.M. Pijut. 2008. Regeneration of plants from Fraxinus pennsylvanica hypocotyls and cotyledons. Sci. Hort. 118:74-79.

Fan, X.M., D.Y. Yuan, X.F. Tan, Y.L. Zeng, and Z.N. Jiang. 2011. Establishment of the high efficiency regeneration system of Camellia oleifera cotyledon and young embryo. Hubei Agr. Sci. 50:1201-1204. (in Chinese with English abstract).

Feas, X., L.M. Estevinho, C. Salinero, P. Vela, M.J. Sainz, M.P. Vazquez-Tato, and J.A. Seijas. 2013. Triacylglyceride, antioxidant and antimicrobial features of virgin Camellia oleifera, C. reticulata and C. sasanqua oils. Molecules 18:4573-4587.

Grzebelus, E., M. Szklarczyk, and R. Baranski. 2012. An improved protocol for plant regeneration from leaf- and hypocotyl-derived protoplasts of carrot. Plant Cell Tiss. Org. Cult. 109:101-109.

Gulati, A. and P.K. Jaiwal. 1994. Plant regeneration from cotyledonary node explants of mungbean (Vigna radiata (L.) Wilczek). Plant Cell Rpt. 13:523-527.

Hu, Y.L., X.H. Yao, H.D. Ren, K.L. Wang, and W. Long. 2014. Study on somatic embryogenesis regeneration system in Camellia oleifera. J. Nanjing Forest. Univ. 38:160-164. (Natural Sciences Edition).

Huang, H., J.C. Li, K.X. OuYang, X.H. Zhao, P. Li, B.Y. Liao, and X.Y. Chen. 2014. Direct adventitious shoot organogenesis and plant regeneration from cotyledon explants in Neolamarckia cadamba. Plant Biotechnol. 31:115-121.

Joshi, A. and S.L. Kothari. 2007. High copper levels in the medium improve shoot bud differentiation and elongation from the cultured cotyledons of Capsicum annuum L. Plant Cell Tiss. Org. Cult. 88:127-133.

Ju, H.J., J. Jeyakumar, M. Kamaraj, N. Praveen, I.M. Chung, S.H. Kim, and M. Thiruvengadam. 2014. High frequency somatic embryogenesis and plant regeneration from hypocotyl and leaf explants of gherkin (Cucumis anguria L.). Sci. Hort. 169:161-168.

Kahia, J., P.K. Sallah, L. Diby, C. Kouame, M. Kirika, S. Niyitegeka, and T. Asiimwe. 2015. A novel regeneration system for tamarillo (Cyphomandra betacea) via organogenesis from hypocotyl, leaf, and root explants. HortScience 50:1375-1378.

Kamal, G.B., K.G. Illich, and A. Asadollah. 2007. Effects of genotype, explants type and nutrient medium components on canola (Brassica napus L.) shoot in vitro organogenesis. Afr. J. Biotechnol. 6:861-867.

Li, Z., X.F. Tan, J. Yuan, K. Lu, L. Zhang, Q. Lin, and J.B. Lv. 2014. Tissue culture and highly efficient rooting of Camellia oleifera 'Huashuo'. Plant Physiol. J. 50:1721-1726. (in Chinese with English abstract).

Liao, S.J., D.L. Ji, and H.R. Tong. 2005. Study on fatty acid compostion and nutrition health protection function of the oil tea Camellia seed oil. 6:7-9. (in Chinese with English abstract).

Lin, Q., Z. Li, L. Zhang, H.X. Long, and L.L. Wu. 2016. High-efficiency regeneration of seedlings from hypocotyl explants of tung tree (Vernicia fordii). Intl. J. Agr. Biol. 18:370-376.

Lloyd, G. and B. McCown. 1981. Commercially feasible micropropagation of mountain laurel, Kalmia latifolia, by use of shoot-tip culture. Proc. Intl. Plant Prop. Soc. 30:421-427.

Long, Z.H. and D.P. Wang. 2008. Chemical constituents of olive oil and from C. oleifera seed oil. J. Chin. Cereals Oils Association 23:121123. (in Chinese with English abstract).

Lü, J.F., R. Chen, M.H. Zhang, J.A.T.D. Silva, and G.H. Ma. 2013. Plant regeneration via somatic embryogenesis and shoot organogenesis from immature cotyledons of Camellia nitidissima Chi. J. Plant Physiol. 170:1202-1211.

McClean, P. and K.F. Grafton. 1989. Regeneration of dry bean (Phaseolus vulgaris L.) via organogenesis. Plant Sci. 60:117-122.

Mo, M.R., W.X. Huang, T.L. Huang, and Y. Tang. 2010. Strengthen the development of tea-oil industry in Guangxi province to ensure the safety of national grain and oils. Chin. J. Agr. Res. and Regional Planning 31:47-50.

Mondal, T.K., A. Bhattacharya, M. Laxmikumaran, and P.S. Ahuja. 2004. Recent advances of tea (Camellia sinensis) biotechnology. Plant Cell Tiss. Org. Cult. 76:195-254.

Mondal, T.K. 2011. Camellia, p. 15-39. In: C. Kole (ed.). Wild crop relatives: Genomic and breeding resources. Springer-Verlag, Berlin/ Heidelberg.

Murashige, T. and F. Skoog. 1962. A revised medium for rapid growth and bioassays with tobacco tissue cultures. Physiol. Plant. 15:473-497. 
Patil, V.M., G.A. Dhande, D.M. Thigale, and J.C. Rajput. 2011. Micropropagation of pomegranate (Punica granatum L.) 'Bhagava' cultivar from nodal explant. Afr. J. Biotechnol. 10:18130-18136.

Sanatombi, K. and G.J. Sharma. 2008. In vitro plant regeneration in six cultivars of Capsicum species using different explants. Biol. Plant. 52:141-145.

Sharma, K.K. and T.A. Thorpe. 1989. In vitro regeneration of shoot buds and plantlets from seedling root segments of Brassica napus L. Plant Cell Tiss. Org. Cult. 18:129-141.

Sivanesan, I., M.Y. Lim, and B.R. Jeong. 2011. Somatic embryogenesis and plant regeneration from leaf and petiole explants of Campanula punctate Lam. var. rubriflora Makino. Plant Cell Tiss. Org. Cult. 107:365-369.

Song, J.Y., N.S. Mattson, and B.R. Jeong. 2011. Efficiency of shoot regeneration from leaf, stem, petiole and petal explants of six cultivars of Chrysanthemum morifolium. Plant Cell Tiss. Org. Cult. 107:295-304.
Stevens, M.E. and P.M. Pijut. 2012. Hypocotyl derived in vitro regeneration of pumpkin ash (Fraxinus profunda). Plant Cell Tiss. Org. Cult. 108:129-135.

Sujatha, M., S. Vijay, S. Vasavi, N. Sivaraj, and S.C. Rao. 2012. Combination of thidiazuron and 2-isopentenyladenine promotes highly efficient adventitious shoot regeneration from cotyledons of mature sunflower (Helianthus annuus L.) seeds. Plant Cell Tiss. Org. Cult. 111:359-372.

Tabrett, A.M. and N. Hammatt. 1992. Regeneration of shoots from embryo hypocotyls of common ash (Fraxinus excelsior). Plant Cell Rpt. 11:514-518.

Warkentin, T.D. and A. McHughen. 1993. Regeneration from lentil cotyledonary nodes and potential of this explant for transformation by Agrobacterium tumefaciens. Lens Newsl. 20:26-28.

Wong, K.W. and C.S. Loh. 1988. In vitro regeneration of plantlets from root segments of Brassica alboglabra bailey. Sci. Hort. 35:7-14.
Yang, Y.J., D.L. Zhang, Z.H. Li, X.L. Jin, and J.Y. Dong. 2015. Immature embryo germination and its micropropagation of Ilex crenata Thunb. HortScience 50:733-737.

Yuan, D.Y., X.M. Fan, X.F. Tan, Y.L. Zeng, J. Tang, and Y. Yang. 2013. Culture in vitro and rapid propagation techniques of buds and leafs in Camellia oleifera. J. Nanjing Forest. Univ. 37:35-39. (Natural Sciences Edition).

Zhang, Z.J., S.P. Luo, Y.L. Li, F.C. Bi, and X.F. Tan. 2005. Plant Regeneration through Somatic Embryogenesis Formationfrom Cotyledons of Camellia oleifera Clone. Chin. Bul. Bot. 22:43-49. (in Chinese with English abstract).

Zhuang, R.L. 2008. Comprehensive utilization of tea-oil fruits, p. 339-346. In: Xiao Jifu (ed.). Tea-oil tree (Camellia oleifera Abel) of China. Chinese Forestry Publish House, Beijing. (in Chinese without English abstract). 